\title{
Rotavirus A infections and reinfections: genotyping and vaccine implications
}

\author{
Paulo S. S. Costa ${ }^{1}$, Divina D. P. Cardoso2 ${ }^{2}$ Sandra J. F. E. Grisi3, Paula A. Silva ${ }^{4}$, \\ Fabíola Fiaccadori ${ }^{4}$, Menira B. L. D. Souza ${ }^{4}$, Rodrigo A. T. Santos ${ }^{4}$
}

\begin{abstract}
Objective: To identify rotavirus $A$ and the most prevalent $G$ and $P$ genotypes in children with acute diarrhea, and to the describe the occurrence of rotavirus infection and reinfection.

Methods: Group A rotavirus specimens were obtained from fecal samples from children with acute diarrhea in Goiânia, state of Goiás, Brazil from July 2000 to October 2002. Rotavirus A positive children and control group (children of the same age and sex, without diarrhea and with no evidence of rotavirus in the first fecal samples) were followed prospectively during one year. All rotavirus A positive samples were genotyped using RT-PCR/nested-PCR.

Results: A total of 77 group A rotavirus strains (37.2\%) were identified in the diarrheic samples of 207 children. The following G genotypes were identified: G1 (62.3\%), G9 (34.4\%) and G4 (3.3\%). With regard to $\mathrm{P}$ genotyping, $59 \%$ were characterized as $\mathrm{P}[8], 7.7 \%$ as $\mathrm{P}[6], 23.1 \%$ as $\mathrm{P}[6]+\mathrm{P}[8], 7.7 \%$ as $P[4]+P[8]$ and $2.6 \%$ as $P[4]+P[8]$. The following associations were observed: $G 1 P[8](77.8 \%)$, G9P[8] (11.1\%), G4P[8] (5.6\%) and G1P[6] (5.6\%). No reinfection was observed in the 40 rotavirus A $(+)$ children. However, but two of 40 children who were initially negative for this agent developed rotavirus infection during the same period.
\end{abstract}

Conclusions: The predominant $G$ and $P$ genotypes observed were similar to those found in new vaccines. No reinfection occurred during one-year of follow-up for any of the genotypes identified.

J Pediatr (Rio J). 2004;80(2):119-22: Diarrhea, infantile, rotavirus, genotype, prospective studies.

\section{Introduction}

Rotaviruses are the most common cause of acute childhood diarrhea in both developed and developing countries. ${ }^{1}$ Around 125 million rotavirus-induced diarrhea episodes occur annually worldwide, resulting in 500,000 to 600,000 deaths. ${ }^{2,3}$ Epidemiological surveys performed on a global scale ${ }^{4}$ observed incidences of 12 to $71 \%$

1. PhD. Associate professor, Department of Pediatrics and Child Care, School of Medicine, Universidade Federal de Goiás (UFG), Goiânia, GO, Brazil.

2. Professor, Institute of Tropical Pathology and Public Health, Universidade Federal de Goiás (UFG), Goiânia, GO, Brazil.

3. Professor, Children's Institute, School of Medicine, Universidade de São paulo (USP), São Paulo, SP, Brazil.

4. Graduate student, Institute of Tropical Pathology and Public Health, Universidade Federal de Goiás (UFG), Goiânia, GO, Brazil.

Financial support: Fundação de Apoio à Pesquisa (UFG) and CAPES.

Manuscript received Sep 09 2003, accepted for publication Jan 092004. (average $34 \%$ ) of rotavirus identification among children less than three years old suffering from acute diarrhea. Data reviewed from Brazil demonstrates variation in gastroenteritis incidence associated with rotavirus in children treated at clinics or hospitals, in the order of 12 to $42 \% .^{5-7}$

Type A Rotaviruses are classified into G genotypes and $P$ according to variations antigens caused by the structural proteins VP7 and VP4, respectively. There is a global predominance of samples characterized as G1P[8]. ${ }^{8,9}$

The worldwide impact of rotavirus infection has resulted in the development of vaccination strategies capable in reducing morbidity and mortality. The tetravalent vaccine (Rotashield ${ }^{\mathrm{TM}}$ ) was suspended due to a potential (and controversial) association with intussusception. ${ }^{10-12} \mathrm{New}$ vaccine candidates have been examined in recent studies. ${ }^{13-15}$ 
The current study assessed occurrence of re-infection by rotavirus and mapped prevalent genotypes with the intention of contributing to the development of safe and effective prevention procedures and also to the planning of Rotavirus A induced diarrhea control activities.

\section{Patients and methods}

Two hundred and seven children with acute diarrhea where studied. They were recruited from those treated at the walk-in centers and infirmaries of the Pediatrics and Childcare Department of the Universidade Federal de Goiás Medical Faculty and the Hospital Materno Infantil de Goiânia - Goiás, during the period between July 2000 and October 2002. Inclusion criteria were the presence of acute diarrhea, defined as three or more liquid or semiliquid evacuations per day. Those responsible for the children who met the criteria had the study explained to them and, agreeing to the child's participation, signed an informed consent for approved by the Ethics Committee of the Hospital das Clínicas at FMUSP.

A total of 46 of the children with acute diarrhea who were identified as having rotavirus in fecal samples and whose guardians gave consent to participate in outpatients follow-up were selected for a one-year, prospective study. An equal number of children, who did not have acute diarrhea and had no evidence of rotavirus in their fecal samples, were paired for age and sex and enrolled as the control group, observing the same ethical principles as before.

Both groups were observed for diarrhea episodes, associated or not with symptomatic or asymptomatic rotavirus infections, for the period of the study by means of fecal samples. Samples were taken for rotavirus identification on day zero (recruitment to study), and monthly thereafter for one year (in addition to samples taken during acute diarrhea episodes ) from children from both the Rotavirus A positive group and the control group.

Rotaviruses were identified in fecal samples using polyacrylamide gel electrophoresis (PAGE) ${ }^{16}$ and by combined enzyme immunoassay for rotavirus and adenovirus (EIARA). ${ }^{17}$

Rotavirus A genotypes were identified by polymerase chain reaction and by Nested-PCR for differentiation between VP4 proteins (P genotype P) and VP7 (G genotypes). The first amplification reaction $(R T-P C R)$ employed the consensus primers $9 \operatorname{con} 1 / 9 \operatorname{con} 2$ ( $G$ genotyping) and $4 \operatorname{con} 2 / 4 \operatorname{con} 3$ ( $P$ genotyping). In the sequential Nested-PCR reaction a mixture of specific primers was used to identify the genotypesG1, G2, G3, G4, G5, G8, G9 and G10, and another mixture to identify genotypes $P[4], P[6], P[8], P[9]$ and $P[10]$. After amplification, the products obtained from each fecal sample by $R T-P C R$ and Nested-PCR were examined in agarose gel, viewed with an ultraviolet transilluminator and analyzed in comparison with a standard molecular weight.
Statistical analysis was performed using Fisher's exact test, with the level of rejection of the null hypothesis set at $5 \%$ (alpha error 0.05 ), with a $95 \%$ confidence interval.

\section{Results}

Two hundred and seven children with acute diarrhea were studied. Of these, $77(37.2 \%)$ were positive for Rotavirus A when the first sample was collected and 46 of these were followed up at outpatients. Similarly, 46 children who had not exhibited acute diarrhea on recruitment and had not presented rotavirus in their first fecal samples were paired for age and sex, making up the control group. A total of 766 fecal samples were collected over the year for both groups; six children from each group were excluded after abandoning follow-up.

It proved possible to identify $G$ genotypes in 61 (79.2\%) of the 77 Rotavirus A samples. The G1 genotype was the most prevalent, occurring in $38(62.3 \%)$ of the genotyped samples, followed by genotype G9, occurring in $21(34.4 \%)$ samples and G4 in two samples (3.4\%).

$P$ genotypes were identified in $39(50.6 \%)$ of the 77 Rotavirus A samples. The P[8] genotype was the most prevalent, identified in $23(59.0 \%)$ of the genotyped samples. The $\mathrm{P}[6]$ genotype was observed in three (7.7\%) samples. A total of 16 samples were positive for more than one $\mathrm{P}$ genotype, with samples being identified with the pairings $P[6]+P[8](23.1 \%), P[4]+P[8](7.7 \%)$ and $P[4]+P[6](2.6 \%)$.

It was possible to correlate $\mathrm{G}$ and $\mathrm{P}$ genotypes in a total of 18 samples $(23.4 \%)$, with a predominance ( $p<$ $0.05)$ of samples characterized as G1P[8] (77.8\%) compared with G9P[8] (11.1\%), G4P[8] (5.6\%) and G1P[6] (5.6\%) (Figure 1).

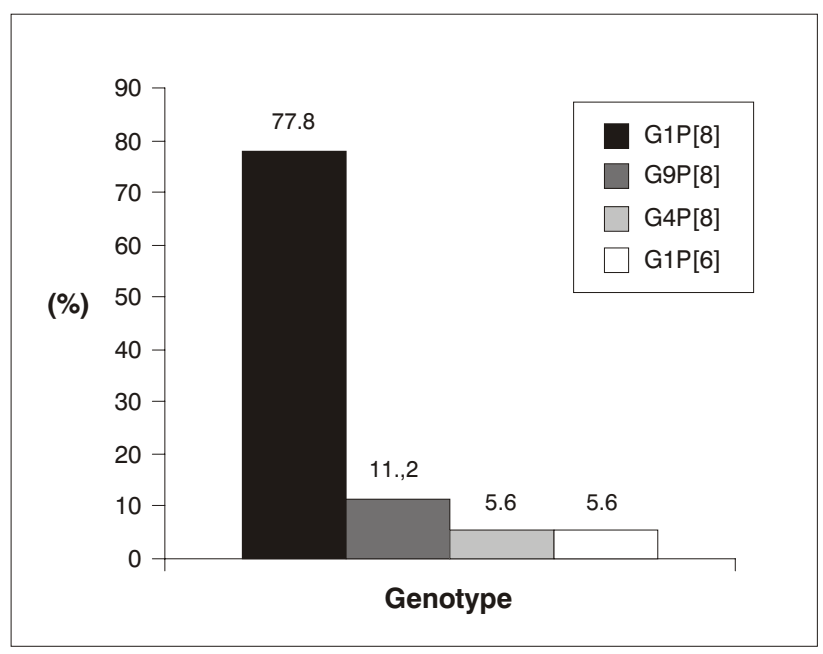

Figure 1 - Distribution of 18 samples of rotavirus A identified with genotypes $\mathrm{G}$ and $\mathrm{P}$ during the whole period of collection 
The 40 children in the Rotavirus A ( + ) follow-up group had an average age of 19.2 months. Nineteen patients were male and 21 were female. Three hundred and eighty samples were collected from this group over the observation period. A total of 51 diarrhea episodes were observed (an average of 1.3 episodes per child per year). Rotavirus was not identified in any of the samples collected from any of the children in this group during the follow-up period.

The control group, also composed of 40 children, had an average age of 19.7 months. Twenty children were male and 20 were female. Three hundred and eighty-six fecal samples were collected from the control group. A total of 48 diarrhea episodes were observed in this group, with an average of 1.2 episodes per child per year. Rotavirus was identified in the feces of two of the children in this group, associated with diarrhea, giving an incidence of 0.05 rotavirus infections per child per year.

\section{Discussion}

From the total of 207 samples collected from children with acute diarrhea, positive Rotavirus A results made up $37.2 \%$. In general, similar data is observed in published literature. ${ }^{4-6}$

Genotype G1 predominated among the genotyped samples, although elevated percentages of G9 were also detected and only two samples were identified as G4. A number of different have described a predominance of samples defined as G1-G4.5,8,9,18,19 In contrast, studies also demonstrate an increasing level of identification of unusual serotypes, such as genotype G9, occurring in $18.1 \%$ of infections by rotavirus in Australia. 20 This fact highlights the possibility that new and emerging serotypes will have an impact on vaccination strategies, resulting in wider-ranging vaccines that cover genotypes other than G1-G4.

In terms of $\mathrm{G}$ and $\mathrm{P}$ genotypes in association, there was a predominance of samples defined as G1P[8]. On a global scale the G1P[8] genotype stands out as the most prevalent, $8,9,21,22$ which could give a basis for monovalent human vaccines specific to G1P[8] (Rotarix ${ }^{T M}$ - Glaxo Smithkline and Avant Imunotherapeutics, Inc, Needham, MA, USA), including in our country.

This prospective study of children with Rotavirus $A$ and of the control patients found no evidence of reinfection by rotavirus, which is in contrast with a number of different follow-up studies that obtained variable levels of rotavirus reinfection, $7,23-28$ which levels were higher in studies that followed patients from birth $13,23,24$ and in studies following restricted communities, such as indigenous populations or children at day-care centers, $25,27,28$ In contrast with this, a wide-ranging study performed in Finland, ${ }^{29}$ did not identify, in common with our observations, rotavirus reinfection. It is possible that this fact could be related to a possible protective effect conferred by natural rotavirus infections that had occurred prior to the one-year observation period.
Another relevant factor was the detection of two symptomatic rotavirus infections during the observation of the control patients. The incidence of infections by rotavirus observed by some authors presents a variation of 0.07 to 0.8 episodes per child per year $13,25,30,31$ during observation of children from birth to two or three years of age. Such levels are greater than those observed in the current study, in the order of 0.05 episodes of rotavirus infections per child per year in the control group, which could be explained by the older age group since the control group was paired for age with a group of children already infected by rotavirus. Based on a study of serological prevalence 24,32 and on the estimate that virtually all children have been infected by rotavirus at least once by the age of five, 33 it is possible that a percentage of the children in the control group already had a certain level of protection resulting from previous infections by rotavirus that were not detected by this study.

This study intends to contribute to knowledge about infections by rotaviruses of group $A$ in children, by means of vigilance of the $G$ and $P$ genotypes prevalent in the region. Thus, it intends to provide support for future research into prophylaxis in our country, since further studies should be performed in the continued vigilance of those genotypes prevalent in our country, towards the definitive implementation of effective preventative measures in the field of rotavirus infection.

\section{Acknowledgements}

We are grateful for the financial support afforded exclusively by the Research Support Foundation (Fundação de Apoio à Pesquisa - UFG) and CAPES.

\section{References}

1. Linhares $A C$, Bresee JS. Rotavirus vaccines and vaccination in Latin America. Pan Am J Public Health. 2000;8:305-31.

2. Kapikian $A Z$, Yasutaka $H$, Chanock RM. Rotaviruses. In: Knipe DM, Rowley PM, Griffin DE, Martin MA, Lamb RA, Roizaman B, editors. Fields virology. 4th ed. Philadelphia: Williams \& Wilkins; 2001. p.1787-833.

3. Miller MA, McCann L. Policy analysis of the use of hepatitis B, Haemophilus influenzae type b-, Streptoccus pneumoniaeconjugate and rotavirus vaccines in national immunization schedules. Health Econom. 2001;9:19-35.

4. de Zoysa I, Feachem RG. Interventions for the control of diarrhea diseases among young children: rotavirus and cholera immunization. Bull WHO. 1985;63:569-83.

5. Pereira HG, Linhares AC, Candeias JAN, Glass RI. National laboratory surveillance of viral agents of gastroenteritis in Brazil. Bull Pan Am Health Org. 1993;27:224-33.

6. Linhares AC. Epidemiologia das infecções por rotavirus no Brasil e os desafios para o seu controle. Cad Saude Publica. 2000; 16:629-46.

7. Linhares AC, Gabbay YB, Freitas RB, Travassos da Rosa ES, Mascarenhas JDP, Loureiro ECB. Longitudinal study of rotavirus infections among children from Belém, Brazil. Epidemiol Infect. $1989 ; 102: 129-45$.

8. Gentsch JR, Woods PA, Ramacuandran M, Das BK, Leite JP, Alfiere $A$, et al. Review of $G$ and $P$ typing results from a global collection of rotavirus strains: implications for vaccine development. J Infect Dis. 1996;174:30-6. 
9. Iturriza-Gómara M, Isherwood B, Desselberger U, Gray J. Reassortment in vivo: driving force for diversity of human rotavirus strains isolated in the United Kingdom between 1995 and 1999. J Virol. 2001;75:3696-705.

10. American Academy of Pediatrics, Committee on Infectious Diseases. Possible association of intussusception with rotavirus vaccination. Pediatrics. 1999;104:575.

11. Bass DM. Rotavirus vaccinology: good news and bad news. J Ped Gastr Nutr. 2000;30:10-1.

12. Dennehy $\mathrm{PH}$, Breese JS. Rotavirus vaccine and intussusception. Where do we go from here? Inf Dis Clin N Am. 2001;15:512-32.

13. Clements-Mann ML, Dudas R, Hoshino $Y$, Nehring $P$, Sperber $E$, Wagner $M$, et al. Safety and immunogenicity of live attenuated quadrivalent human-bovine (UK) reassortant rotavirus vaccine administered with childhood vaccines to infants. Vaccine. 2001;19:4676-84.

14. Bernstein DI, Sack DA, Reisinger K, Rothstein E, Ward RL. Second-year follow-up evaluation of live, attenuated human rotavirus vaccine $89-12$ in healthy infants. J Inf Dis. $2002 ; 186$ : 1487-9.

15. Johansen K, Schroderc U, Svensson L. Immunogenicity and protective efficacy of a formalin-inactivated rotavirus vaccine combined with lipid adjuvants. Vaccine. In Press 2003.

16. Pereira HG, Azeredo RS, Leite JPG, Barth OM, Sutmoller F, Farias $V$, et al. Comparison of polyacrilamide gel electrophoresis (PAGE), immunoelectron microscopy (IEM) and enzyme immunoassay (EIA) for the rapid diagnosis of rotavirus infection in children. Mem Inst Oswaldo Cruz. 1983;78:483-90.

17. Pereira HG, Azeredo RS, Leite JPG, Andrade ZP, Castro LA. Combined enzyme immunoassay for rotavirus and adenovirus (EIARA). J Virol Methods. 1985;10:21-8.

18. Cardoso DDP, Soares CMA, Souza MBLD, Azevedo MSP, Martins RMB, Queiróz DAO, et al. Epidemiological features of rotavirus infection in Goiânia, Goiás, Brazil, from 1986 to 2000. Mem Inst Oswaldo Cruz. In Press 2003.

19. Beards GM, Desselberger U, Flewett TH. Temporal and geographical distributions of human rotavirus serotypes, 1983 to 1988. J Clin Microbiol. 1989;27(12):2827-33.

20. Kirkwood C, Bogdanovic-Sakran N, Clark R, Masendycz P, Bishop R, Barnes G. Report of the Australian rotavirus surveillance program, 2000/2001. Commun Dis Intell. 2002;26(4):537-40.

21. Ramachandran M, Das BK, Vij A, Kumar R, Kesari N, Rawat H, et al. Unusual diversity of human rotavirus $\mathrm{G}$ an $\mathrm{P}$ genotypes in India. J Clin Microbiol. 1996;34:436-9.

22. Mascarenhas JDP, Linhares AC, Gabbay YB, Leite JPG. Detection and characterization of rotavirus $G$ and $P$ types from children participating in a rotavirus vaccine trial in Belém, Brazil. Mem Inst Oswaldo Cruz. 2002;97:113-7.
23. Wyatt RG, Yolken RH, Urrutia J], Mata L, Greenberg HB, Chanock RM, et al. Diarrhea associated with rotavirus in rural Guatemala: a longitudinal study of 24 infants and young children. Am J Trop Med Hyg. 1979;28(2):325-8.

24. Bishop RF, Barnes GL, Cipriani E, Lund JS. Clinical Immunity after neonatal rotavirus infection. N Engl J Med. 1983;309:72-6.

25. Mata L, Simhon A, Urrutia JJ, Kronmal RA, Fernández R, García B. Epidemiology of rotavirus in cohort of 45 Guatemalan Mayan Indian children observed from birth to the age of three years. J Infect Dis. $1983 ; 148: 452-61$.

26. Flores J, Pérez-Schael I, González M, Garcia D, Perez M, Daoud $\mathrm{N}$, Cunto $\mathrm{W}$, et al. Protection against severe rotavirus diarrhoea by rhesus rotavirus vaccine in Venezuelan infants. Lancet. 1987; $1: 882-4$.

27. O'ryan MO, Matson DO, Estes MK, Bartlett AV, Pickering LK. Molecular epidemiology of rotavirus in children attending day care centers in Houston. J Infect Dis. 1990;162:810-6.

28. Moulton LH, Staat MA, Santosham M, Ward RL. The protective effectiveness of natural rotavirus infection in an American Indian population. J Infect Dis. 1998;178:1562-6.

29. Ruuska T, Vesikari T. A prospective study of acute diarrhoea in Finnish children from birth to $2 \frac{1}{2}$ years of age. Acta Paediatr Scand. 1991;80:500-7.

30. Zaki AM, Dupont HL, El Alamy MA, Arafat RR, Amin K, Awad MM, et al. The detection of enteropathogens in acute diarrhea in a family cohort population in rural Egypt. Am J Trop Med Hyg. 1986;35:1013-22.

31. Velázquez FR, Matson DO, Calva JJ, Guerrero L, Morrow AL, Carter-Campbell $S$, et al. Rotavirus infection in infants as protection against subsequent infections. $\mathrm{N}$ Engl J Med. 1996:335:1022-8.

32. Velázquez FR, Matson DO, Guerrero ML, Shults J, Calva JJ, Morrow $A L$, et al. Serum antibody as a marker of protection against natural rotavirus infection and disease. J Inf Dis. 2000;182:1602-9.

33. Cunliffe NA, Hart CA. Rotavirus vaccines: development, current issues and future prospects. J Infect. 2002;45:1-9.

Corresponding author:

Paulo S. S. Costa

Rua J-34, 240 quadra 60 lote 12 Setor Jaó

CEP 74673-520 - Goiânia, GO, Brazil

Tel.: + 55 (62) 204.4075 - Fax: +55 (62) 212.8698

E-mail: plcosta@terra.com.br 